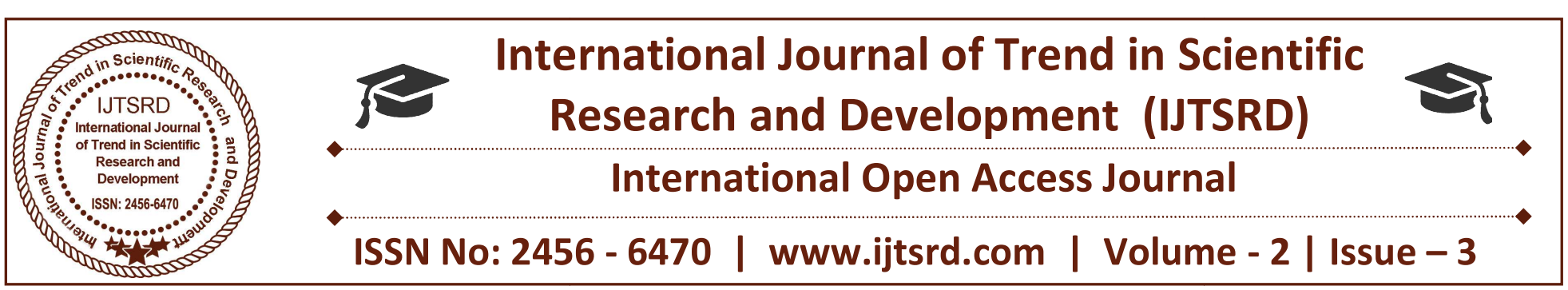

\title{
Secure Authentication to Identify the Human using Finger Printer Profile in Voting System
}

\author{
B. Chandraganesh, J. Nareshkumar, S. Thirumal \\ Department of Computer Science and Engineering, \\ G.K.M. College of Engineering and Technology, Chennai, Tamil Nadu, India
}

\begin{abstract}
The problem of voting is still critical in terms of safety and security. This paper deals with the design and development of a web-based voting system using fingerprint and adhaar card in order to provide a high performance with high security to the voting system. Also we use web technology to make the voting system more practical. The proposed Online Voting System allows the voters to scan their fingerprint, which is then matched with an already saved image within a database that is retrieved from adhaar card database of the government. The voting system is managed in a simpler way as all the users must login by adhaar card number and password and click on his/her favorable candidates to cast the vote. In this System we also restrict the Ineligible voters with respect to age. This will increase the voting percentage in India and reduces the cost of voting process. By using biometric fingerprint it provides enough security which reduces the false votes.
\end{abstract}

Keywords: Biometric recognition, aadhar card, synthetic database, verification, voting

\section{INTRODUCTION}

Online voting system project is implemented in Asp.net platform using Mysql database as back end. Main aim of online voting system is to develop an online application like online reservation system, for citizens who are above 18 years of age to vote through online. Using these system citizens information of Indian can vote through online without visiting polling booth. A centralized database is maintained by election commission of india where citizens information is maintained when citizens information is maintained whenever citizen is using online voting

system his/her information is authenticated with the data present in database if user is not in the list he/she cannot use online voting system. Users are provided with a online registration form and submit details these details are compared with username and password using this information user can login and vote using biometric fingerprint. If conditions are not correct entry will be canceled and user cannot able to vote. It might be reduced the false voters and votes.

\section{I RELATED WORKS}

Robust Biometric Recognition From Palm Depth Images for Gloved Hands, P. Nguyen, Member (2015). The from palm a depth-based solution for palm biometric recognition. It can be extracts fingers and palm of users. palm biometric recognition techniques depend upon palm appearance features of humans. Low computational cost multilayer graphbased segmentation algorithms for hand recognition on mobile phones, Danil de Santos-sierra (2014). A segmentation method based on multilayer graph theory that performs accurate hand segmentation without being computationally. This segmentation algorithm hand recognition for mobile phones. known segmentation algorithms (NCuts and KMeans) by using a synthetic database with over 400000 images. Palm-Print Classification by Global Features, Bob Zhang, 2013.Meng-Hui, Wang (2016) were explained the concept of Application of extension method and chaos theory in ECG identity recognition system. Surface, Vivek Kanhangad (2011) were used the technique Contactless and Pose Invariant Biometric Identification Using Hand surface. Anil K. Jain, Fellow, IEEE, Arun Ross, Member, IEEE, and Salil 
Prabhakar, Member, IEEE (2004) were proposed an Introduction to Biometric Recognition.

\section{PROPOSED SYSTEM}

The Biometric online voting system with biometric fingerprint using aadhar card. Only eligible voters are permitted to cast their vote. removes human fallibility from the tabulation process and makes your election results available within seconds of the close of the election. no paper ballots, no postage and no printing allows voters to go back and correct any mistakes before final submission of their ballot. Once a ballot has been submitted however, it is final and can not be altered.

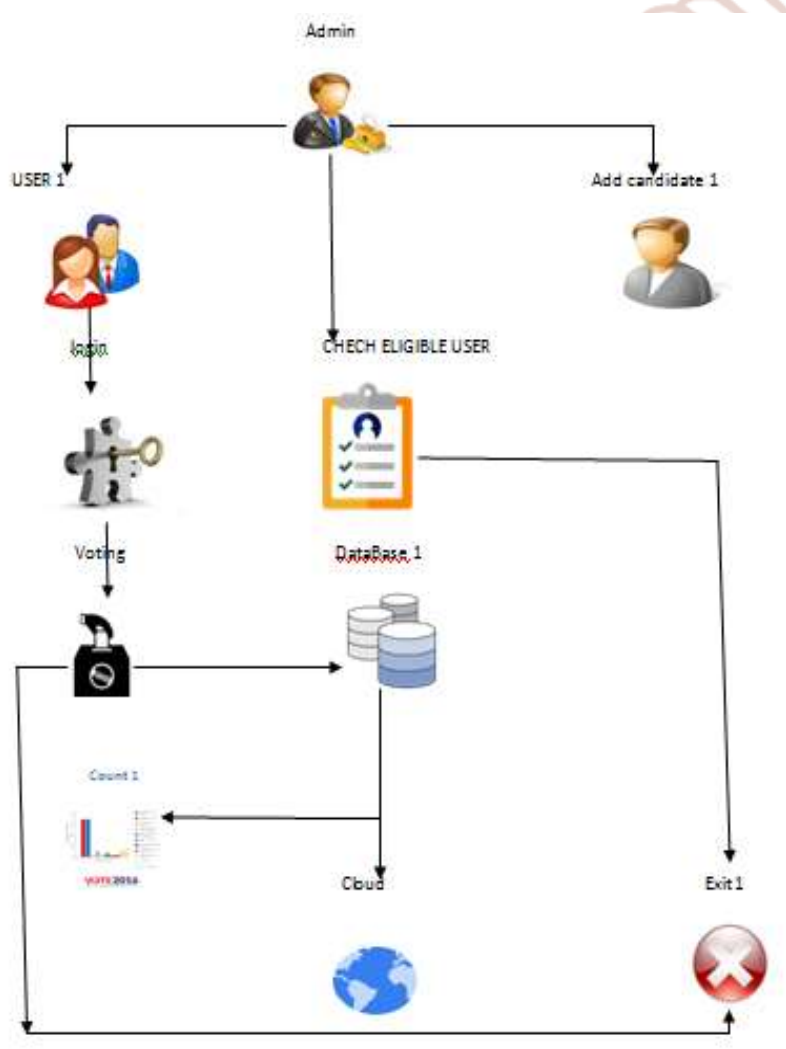

Fig 1: Architecture of OVS

\section{A. Home}

It is the welcome page of the website, having all the features options of the website. It includes all the features like registration, login, election commission login This module describes the authentication so Admin and Users enters the application through login. Both Admin and Users must have the separate username password.

- Election commission Login

- User Login

\section{B. Registration}

This is the registration page, where the voter can be register themseleves. They all have to enter basic informations best of their known and also voters want to enter their aadhardcard number and voter id number to register themseleves. All the information in the website is saved in the respective database. In this module we are implementing verification and validation process based on username, phone number, and account number. This process is created by Aadhar application linked with aadhar server and stored details in database.

\section{Login}

After registering into the website, this information is saved to the database and sent to the election commission. The user can login to the website with is unique AADHARCARD and FINGERPRINT. After finshing the login voter can poll the vote to their favour candidate using their fingerprint which is match with aadharcard. An voter can view the candidate details in the pooling options. This module is used to identify the specific constitution volume of voter and also viewing the list of candidates those who are nominated for particular volume in particular position.

\section{Admin login}

An admin login is used by election commission officer. The election commission officer authority to accept eligible users only otherwise he/she has right to reject their registration. Election commission officer only have the authority to view the results and declare the results. He/she doesn't have the authority to change the results or any other activities. 


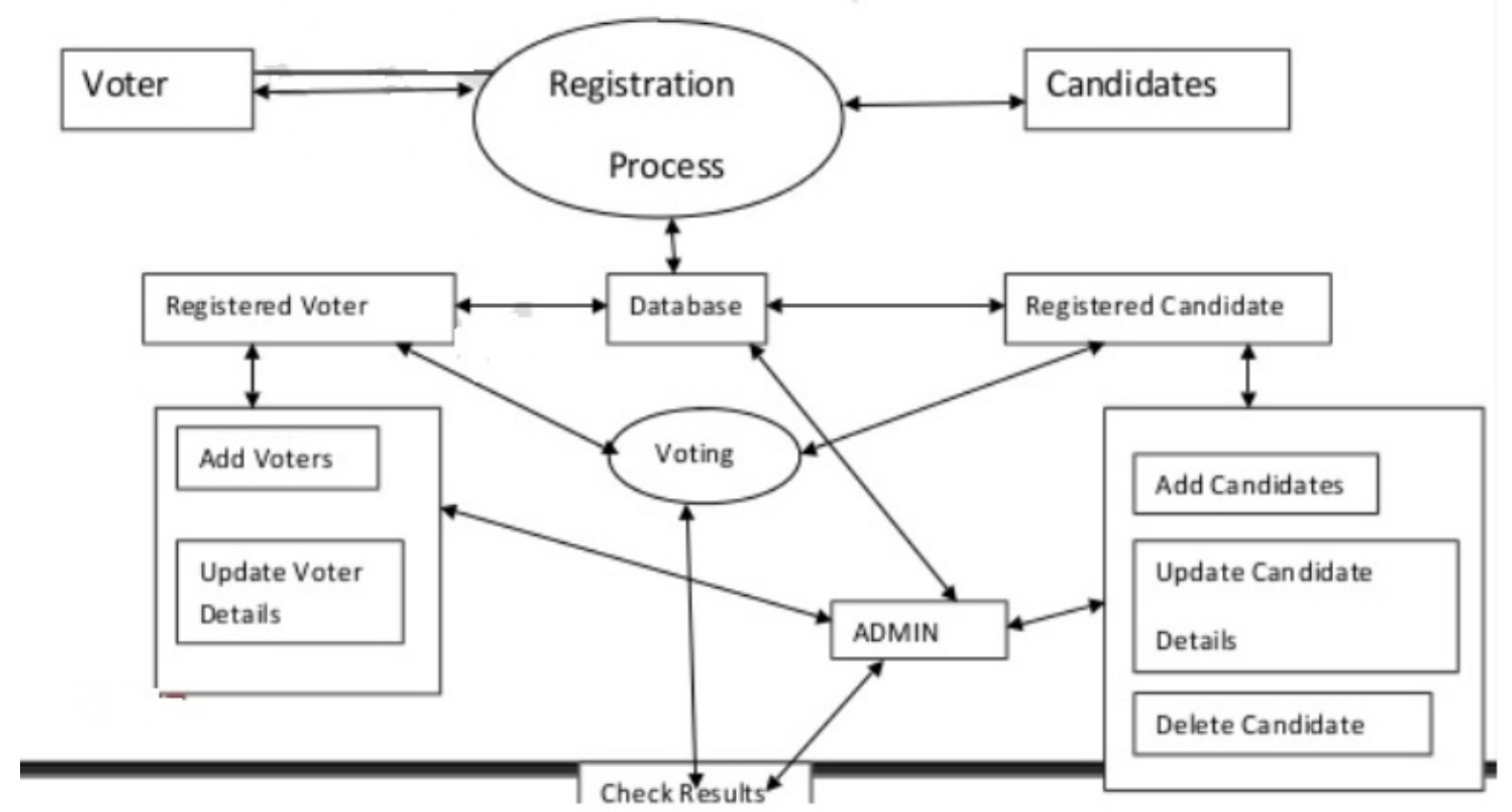

\section{CONCLUSIONS}

Our proposals enables a voter to cast his/her vote through internet without going to voting booth and additionally registering himself/herself for voting in advance, proxy vote or double voting is not possible, fast to access, highly secure, easy to maintain all the information of voting, highly efficient and flexible, easy to declare the results within one or two hour. Hence by this voting percentage will increase drastically. The using of online voting has the capability to reduce or remove unwanted human errors. In addition to its reliability, online voting can handle multiple modalities, and provider better scalability for large elections. Online voting is also an excellent mechanism that does not require geographical proximity of the voters. For example, soldiers can poll their vote in online

\section{REFERENCES}

1. Wang, M.H. and Lee, Z.Y., 2016, July. Application of extension method and chaos theory in ECG identity recognition system. In Industrial Informatics (INDIN), 2016 IEEE 14th International Conference on (pp. 1247-1251). IEEE.

2. Jain, A.K., Ross, A. and Prabhakar, S., 2004. An introduction to biometric recognition. IEEE Transactions on circuits and systems for video technology, 14(1), pp.4-20..
3. Kanhangad, V., Kumar, A. and Zhang, D., 2011. Contactless and pose invariant biometric identification using hand surface. IEEE transactions on image processing, 20(5), pp.14151424.

4. de Santos-Sierra, D., Arriaga-Gómez, M.F., Bailador, G. and Sánchez-Ávila, C., 2014, October. Low computational cost multilayer graph-based segmentation algorithms for hand recognition on mobile phones. In Security Technology (ICCST), 2014 International Carnahan Conference on (pp. 1-5). IEEE..

5. Han, C.C., Cheng, H.L., Lin, C.L. and Fan, K.C., 2003. Personal authentication using palm-print features. Pattern recognition, 36(2), pp.371381Anderson, R., Wiryana, F., Ariesta, M.C. and Kusuma, G.P., 2017. Sign Language Recognition Application Systems for Deaf-Mute People: A Review Based on Input-Process-Output. Procedia Computer Science, 116, pp.441-448.

6. Nguyen, B.P., Tay, W.L. and Chui, C.K., 2015. Robust biometric recognition from palm depth images for gloved hands. IEEE Transactions on Human-Machine Systems, 45(6), pp.799-804.

7. Kanhangad, V., Kumar, A. and Zhang, D., 2011. A unified framework for contactless hand verification. IEEE transactions on information forensics and security, 6(3), pp.1014 